\title{
Lung segmentectomy: does it offer a real functional benefit over lobectomy?
}

\author{
Anne Charloux ${ }^{1,2}$ and Elisabeth Quoix ${ }^{3}$
}

Affiliations: ${ }^{1}$ Physiology and Functional Explorations Dept, University Hospital, Strasbourg, France. ${ }^{2}$ EA 3072 , Federation of Translational Medicine, Strasbourg University, Strasbourg, France. ${ }^{3}$ Pulmonology Dept, University Hospital, Strasbourg, France.

Correspondence: Anne Charloux, Service de Physiologie et d'Explorations Fonctionnelles, Nouvel Hôpital Civil, Hôpitaux Universitaires de Strasbourg, BP 426, 1 Place de l'Hôpital, 67091 Strasbourg Cedex, France. E-mail: anne.charlouxachru-strasbourg.fr

@ERSpublications

Lung segmentectomy offers mild post-operative to small long-term functional benefits over lobectomy http://ow.ly/dcPQ30fuCU9

Cite this article as: Charloux A, Quoix E. Lung segmentectomy: does it offer a real functional benefit over lobectomy? Eur Respir Rev 2017; 26: 170079 [https://doi.org/10.1183/16000617.0079-2017].

ABSTRACT Anatomical segmentectomy has been developed to offer better pulmonary function preservation than lobectomy, in stage IA lung cancer. Despite the retrospective nature of most of the studies and the lack of randomised studies, a substantial body of literature today allows us to evaluate to what extent lung function decreases after segmentectomy and whether segmentectomy offers a real functional benefit over lobectomy. From the available series, it emerges that the mean decrease in forced expiratory volume in $1 \mathrm{~s}(\mathrm{FEV} 1)$ is low, ranging from $-9 \%$ to $-24 \%$ of the initial value within 2 months and -3 to $-13 \% 12$ months after segmentectomy. This reduction in lung function is significantly lower than that induced by lobectomy, but saves only a few per cent of pre-operative FEV1. Moreover, the published results do not firmly establish the functional benefit of segmentectomy over lobectomy in patients with poor lung function. Some issues remain to be addressed, including whether video-assisted thoracic surgery (VATS) segmentectomy may preserve lung function better than VATS lobectomy in patients with poor lung function, especially within the early days after surgery, and whether this may translate to lowering the functional limit for surgery. Eventually, trials comparing stereotactic ablative body radiotherapy, radiofrequency ablation and segmentectomy functional consequences are warranted.

\section{Introduction}

Anatomical segmentectomy has been implemented to offer better pulmonary function preservation than lobectomy. The rapid integration of this procedure as routine is explained first by the development of computed tomography (CT) screening for lung cancer, which allows the diagnosis of lung cancer at a very early stage (IA). Second, the assumption that reducing the resected lung volume may enhance the possibility of further resections in the case of a second primary lung cancer has provided an additional substantial incentive to perform segmentectomy. The third factor contributing to the development of this procedure was the intent to propose surgical treatment to patients with impaired lung function. Indeed, based on early published studies, the use of segmentectomy in these patients was recommended as an alternative to lobectomy by several task forces, the European Respiratory Society/European Society of Thoracic Surgeons in 2009 [1], the British Thoracic Society in 2010 [2] and the American College of Chest Physicians in 2013 [3]. In addition to survival analysis comparing segmentectomy to lobectomy, several

Received: July 072017 | Accepted: Aug 032017

Conflict of interest: None declared.

Provenance: Submitted article, peer reviewed.

Copyright OERS 2017. ERR articles are open access and distributed under the terms of the Creative Commons Attribution Non-Commercial Licence 4.0. 
recent studies have focused on the functional consequences of lung segmentectomy. In light of these latest results, it is worth reconsidering to what extent lung function decreases after segmentectomy compared to lobectomy and whether segmentectomy offers a real functional benefit over lobectomy. Also, the recent development of stereotactic irradiation or even radiofrequency ablation for early-stage (stage IA) lung cancer deemed inoperable, as an alternative to surgery, further justifies having strong data regarding the advantages and inconveniences of those treatments.

In this article we review all the published articles providing pulmonary function tests (PFTs) performed before and after segmentectomy, and focus on those comparing lobectomy and segmentectomy. We extracted data to examine to what extent pulmonary function is impaired after segmentectomy, if segmentectomy better preserves lung function than lobectomy, if video-assisted thoracic surgery (VATS) segmentectomy further increases the functional benefit attributed to open segmentectomy, and if segmentectomy provides a real functional benefit to patients with poor lung function.

\section{Methods}

We performed a search in the PubMed database using the following strategy: lung neoplasms (MeSH term) AND respiratory function tests (MeSH term) AND (lobectomy AND limited resection) OR (lobectomy AND sublobar resection) OR (lobectomy AND segmentectomy). Only English-language articles and human studies published between January 1, 1990 and December 31, 2016 were included. References of relevant articles were also manually searched to identify potentially eligible articles. We selected the articles providing pre-operative and post-operative lung function studies, or post-operative variations in pulmonary function (figure 1).

\section{Results}

Functional changes after segmentectomy

A total of 16 studies, including 1137 patients [4-19], provided pre- and post-operative functional values (table 1). Forced expiratory volume in $1 \mathrm{~s}\left(\mathrm{FEV}_{1}\right)$ was the most frequently reported functional value, so we focused on this parameter. The mean variation in FEV1 varied widely from one study to another, ranging from $-24 \%$ to $+12 \%$ of the initial value. Only one study reported a gain in FEV1 $(+12 \%)$. This study included patients with impaired lung function and with predicted post-operative FEV $1<40 \%$ [11]. The loss of lung function decreases over time after surgery and a more intelligible picture emerges from

PubMed search: Lung neoplasms AND respiratory function tests AND llobectomy AND limited resection) OR (lobectomy AND sublobar resection) OR (lobectomy AND segmentectomy); human; English; 1990-2016

FIGURE 1 Flow chart showing the results of the bibliographic search. PFT: pulmonary function test.

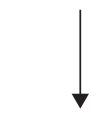

823 articles

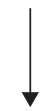

Mention of pre- and postoperative PFT in the abstract

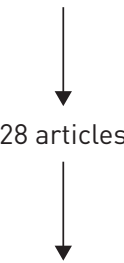

Pre- and post-operative PFT results available in the article

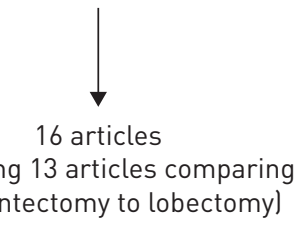




\begin{tabular}{|c|c|c|c|c|c|c|c|c|c|c|}
\hline Ginsberg [4] & 1995 & 71 & Open & $\begin{array}{c}6 \\
12-18\end{array}$ & & $\begin{array}{l}-1.76 \pm 15.3 \\
-5.18 \pm 16.1\end{array}$ & & & & $\begin{array}{l}+1.93 \pm 19.4 \\
+0.52 \pm 22.1\end{array}$ \\
\hline YoshiKaWA [18] & 2002 & 55 & Open & 12 & & $-13.4 \pm 10.4$ & & & & $-11.3 \pm 9.8$ \\
\hline KeEnan [8] & 2004 & 54 & Open & 12 & $55.3 \pm 3.0$ & $-5^{\#}$ & $67.5 \pm 3.0$ & $-17^{\#}$ & $72.8 \pm 2.5$ & $-5^{\#}$ \\
\hline MARTIN-UCAR $_{\text {[11] }}$ & 2005 & 34 & Both & $4(3-6)$ & $45(19-54)$ & $+12(-2$ to +47$)$ & & & & \\
\hline HARADA [5] & 2005 & 38 & $\begin{array}{l}\text { Mini- } \\
\text { thoracotomy }\end{array}$ & $\begin{array}{l}2 \\
6\end{array}$ & $75.0 \pm 3.8$ & $\begin{array}{l}-15^{\#} \\
-12^{\#}\end{array}$ & & & $3.13 \pm 0.67 \mathrm{~L}^{9}$ & $\begin{array}{l}-15^{\#} \\
-10^{\#}\end{array}$ \\
\hline KASHIWABARA [7] & 2009 & 71 & Open & 6 & $109.4 \pm 20.8$ & $\begin{array}{c}\text { Normal FEV } 1 \\
-12.9 \pm 8.7 \\
\text { FEV } \\
-13.8 \pm 9.9\end{array}$ & & & $111.15 \pm 12.3$ & $\begin{array}{c}\text { Normal FEV } 1 \\
-13.4 \pm 8.6 ; \\
\text { FEV } 1<70 \%: \\
-16.0 \pm 11.8\end{array}$ \\
\hline SAITo [14] & 2014 & 52 & Open & $\begin{array}{l}1 \\
6\end{array}$ & $77.6 \pm 7.7$ & $\begin{array}{l}-28 \pm 7 \\
-19 \pm 7\end{array}$ & & & $107.1 \pm 19.9$ & $\begin{array}{l}-14 \pm 6 \\
-10 \pm 5\end{array}$ \\
\hline Hwang [6] & 2015 & 94 & VATS & NA & $101.6 \pm 24.0$ & $-8.9 \pm 10.8$ & $92.7 \pm 17.4$ & & $100.8 \pm 16.3$ & \\
\hline КІм [9] & 2015 & 73 & VATS & $\begin{array}{c}3 \\
12\end{array}$ & $100.1 \pm 18.9$ & $\begin{array}{l}-4.83 \pm 8.74 \\
-2.75 \pm 8.10\end{array}$ & $104.2 \pm 20.7$ & $\begin{array}{l}-3.44 \pm 11.49 \\
-0.38 \pm 22.11\end{array}$ & $99.7 \pm 13.8$ & $\begin{array}{l}-4.45 \pm 7.30 \\
-2.01 \pm 8.33\end{array}$ \\
\hline MACKE [10] & 2015 & 89 & Both & $6-36$ & $79 \pm 22$ & $-4.3 \pm 17.4$ & $63 \pm 22$ & $-3.6 \pm 15.8$ & & \\
\hline Suzukı [15] & 2016 & 37 & Both & $\begin{array}{c}2 \\
7-12\end{array}$ & $73.3 \pm 9$ & $\begin{array}{l}-18.6^{\#} \\
-12.2^{\#}\end{array}$ & & & $3.06 \pm 0.68 \mathrm{~L}^{9}$ & $\begin{array}{l}-18.2^{\#} \\
-6.6^{\#}\end{array}$ \\
\hline
\end{tabular}

Data are expressed as mean \pm SD or mean (range). Variation data are relative to the initial values. VATS: video-assisted thoracic surgery; FEV1: forced expiratory volume in $1 \mathrm{~s}$; DLCO: diffusing capacity of the lung for carbon monoxide; FVC: forced vital capacity; Open: thoracotomy; Both: VATS and thoracotomy; NA: not available. " ${ }^{*}$ calculated from data or extracted from figures; " : absolute values in $L$ given where no $\%$ pred values available; ${ }^{+}$: compared resections $<2$ segments $(<2 \mathrm{seg}), \geqslant 2$ segments $(\geqslant 2 \mathrm{seg})$, and of the left upper division (LUD).

figure 2, which shows the time-course of FEV1 after segmentectomy [4-6, 8-11, 13-16]. Within 2 months after surgery, the loss of FEV1 (mean value of the study) ranged from $-9 \%$ to $-24 \%$ of the initial value in five series (mean of the studies -18\%) [5, 13-16], whereas after 12 months the loss ranged from $-3 \%$ to $-13 \%$ (mean $-7 \%)[4,8,9,16,18]$.

Four studies examined the relationship between the number of resected segments and the loss of pulmonary function. HARADA et al. [5] found a significant relationship using logistic regression. HwANG et al. [6] compared the loss of FEV1 linked to the resection of one, two or three segments and found no statistical difference, but the power of the analysis was not specified. Yоsнімото et al. [19], combining lung function measurement and imaging techniques, showed that the resection of one and two segments preserved $49 \%$ and $35 \%$ of pre-operative FEV1 of each lobe, respectively, whereas the resection of three or four segments preserved a significantly lower fraction (17\% of FEV1). Finally, Nomori et al. [12] compared the functional impact of the resection of $<2$ segments, $\geqslant 2$ segments and of the left upper division, the volume of resected lung increasing from the first to the last group. The differences in loss of FEV1 between groups were statistically significant.

Does segmentectomy preserve lung function better than lobectomy?

13 studies compared the functional consequences of these two procedures, with a total of 1093 lobectomies and 911 segmentectomies. The results are summarised in table 2 and figure 2. Four studies matched the patients' characteristics $[11,13,16,17]$. Five studies were prospective $[4,5,12,13,16]$ and 
FIGURE 2 Attempt to evaluate changes in forced expiratory volume in $1 \mathrm{~s}\left(\mathrm{FEV} \mathrm{V}_{1}\right)$ with time after lobectomy and segmentectomy. Changes are expressed as a percentage of the pre-operative FEV1 value. Logarithmic trendlines are the best-fit curved lines to the data. Data from $[4-6,8-11,13-16]$.

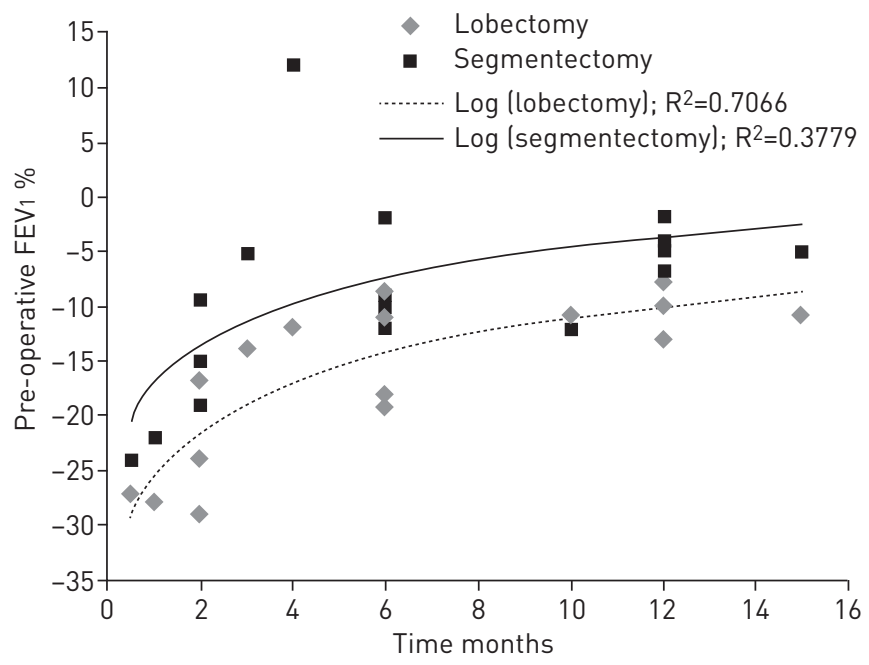

only one was a randomised study [4]. Two studies included wedge resections and not only anatomical segmentectomies $[4,9]$. Only two studies found that reductions in FEV1 did not differ significantly after segmentectomy or lobectomy [6, 15]. Again, when evaluating the difference between lobectomy and segmentectomy, the delay after surgery should be considered. Within 2 months after surgery, the mean loss of FEV1 ranged from $-17 \%$ to $-29 \%$ of initial value after lobectomy (mean $-25 \%$ ) and from $-9 \%$ to $-24 \%$ after segmentectomy (mean -18\%) [5, 13-16]. Beyond 12 months, the mean FEV1 loss ranged from $-8 \%$ to $-13 \%$ of initial value after lobectomy (mean $-11 \%$ ) and from $-2 \%$ to $-7 \%$ after segmentectomy (mean -5\%) [4, 8, 9, 16]. Within 2 months after surgery, the difference between lobectomy and segmentectomy was $3-10 \%$ of initial FEV1, whereas after 12 months, this difference ranged from $4 \%$ to $7 \%$ of initial FEV1. KIM et al. [9] performed a multivariate analysis on a series of 351 VATS lobectomies and segmentectomies and showed that preservation of FEV1 and diffusing capacity of the lung for carbon monoxide (DLCO) values was associated with sublobar resection. Altogether, these studies support the assumption that sublobar resection preserves more lung function than lobectomy, but to a small extent.

It is well known that the largest reduction in lung function occurs during the first days after surgery. Because the earliest functional data were collected 2 weeks after segmentectomy [16], whether the degradation of lung function is reduced very early after segmentectomy compared to lobectomy cannot be evaluated.

\section{Does VATS segmentectomy further increase the functional benefit attributed to open segmentectomy?}

Three series reported functional results after VATS segmentectomy, and six after open segmentectomy [4, $8,13,14,16,18]$, while the others included both procedures. The average loss of FEV1 in these studies was $5 \%(3-9 \%)$ with the VATS procedure (four measurements) and 9\% (2-19\%) with the open procedure (10 measurements), PFTs being performed with at least 1 month delay. Drawing firm conclusions from these studies is difficult. Indeed, no study compared VATS and open segmentectomy. In addition, studies of the early post-operative days, during which the functional benefit of VATS may be of importance, are lacking.

Does segmentectomy provide a real functional benefit to patients with poor lung function?

13 studies provided pre-operative FEV1 values (table 1) [5, 7-18]. In nine studies, the mean value of FEV1 was $>70 \%$ of predicted. Some included patients with poor lung function but did not individualise this subgroup. Two studies focused on patients with impaired FEV1, with a mean pre-operative FEV1 of $55 \%$ [8] and 45\% [11], respectively. One author compared patients with decreased FEV1 $(<70 \%)$ to those with normal FEV1 [7]. In these three last studies open surgery [7, 8] or open surgery and VATS [11] were performed.

The two studies including only patients with impaired lung function showed that segmentectomy spared lung function compared to lobectomy (total number of studied patients: 65). The loss of FEV1 was 5\% versus $10 \%$, respectively, in the study by KeENAN et al. [8]. MARTin-UCAR et al. [11], who matched segmentectomy with lobectomy patients, showed a gain in lung function after segmentectomy $(+12 \%$ FEV1, versus $-12 \%$ after lobectomy). However, Kashiwabara et al. [7] found that segmentectomy had a functional benefit over lobectomy only in patients with $\mathrm{FEV}_{1}>70 \%$ (50 patients). In addition, in patients with emphysema, the variation of FEV 1 was inversely correlated with predicted post-operative FEV 1 in the 
TABLE 2 Studies comparing lobectomy and segmentectomy functional consequences

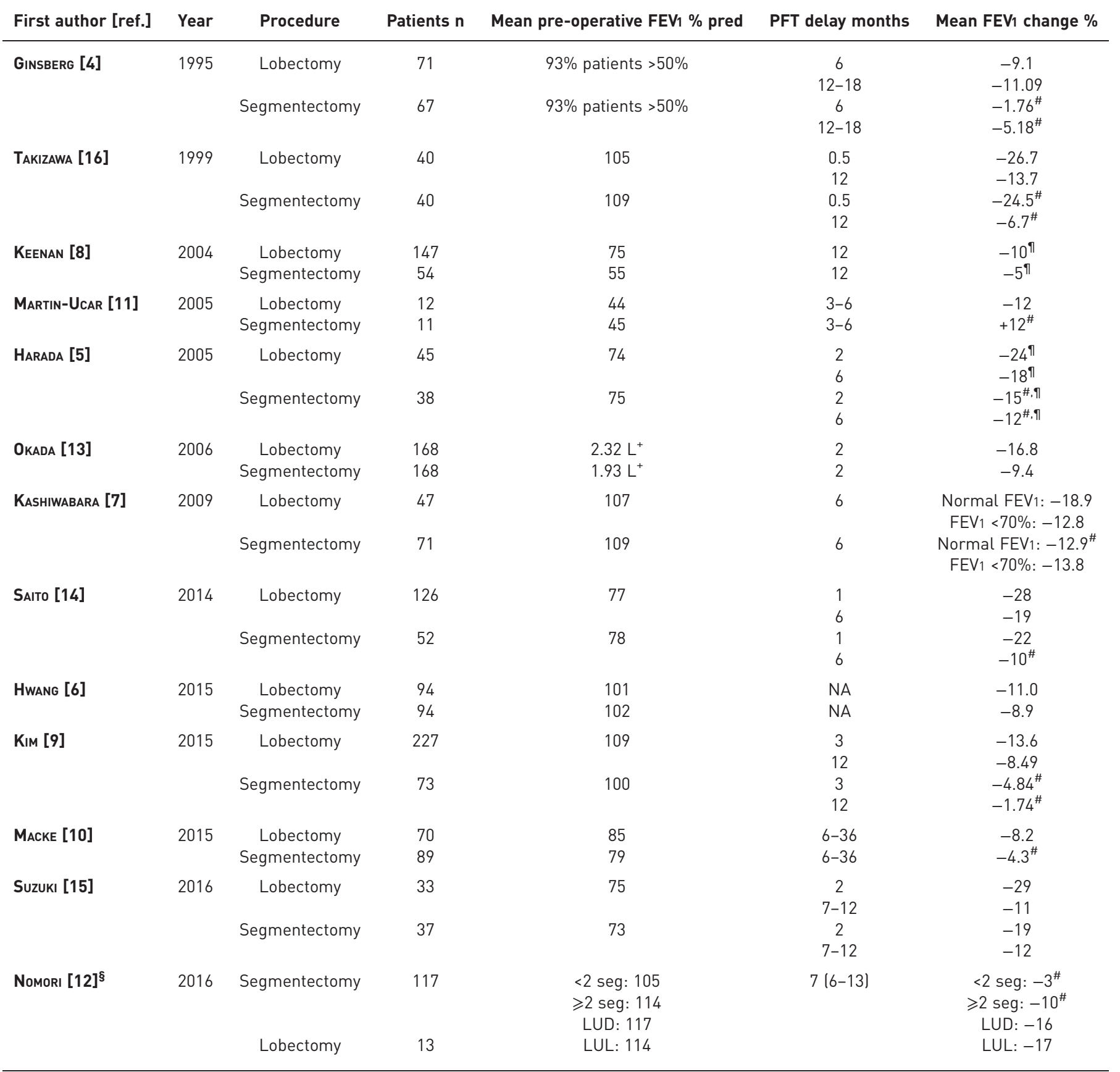

FEV1: forced expiratory volume in $1 \mathrm{~s}$; PFT: pulmonary function test; NA: not available. ${ }^{\#}$ : significant difference between lobectomy and segmentectomy; ${ }^{\text {ๆ: }}$ calculated from data or extracted from figures; ${ }^{+}$: absolute values in $L$ given where no \% pred values available; ${ }^{\S}$ : compared resections $<2$ segments (<2 seg), $\geqslant 2$ segments ( $\geqslant 2 \mathrm{seg}$ ), of the left upper division (LUD) and left upper lobectomy (LUL).

lobectomy group (i.e. the higher the predicted post-operative FEV1, the stronger the loss in FEV1), but not in the segmentectomy group [7].

\section{Comments}

The design, as well as the surgical procedures (number of resected segments, tumour location, VATS or open surgery), varied widely from one study to another, and may explain part of the heterogeneity of the results. The main methodological issues are the retrospective nature of most of the studies and the lack of randomised studies, the lung cancer study group study being the only randomised study [4]. This last point may have led to underestimating of the real benefit of segmentectomy, because patients with the 
poorest condition may have been included in the segmentectomy group rather than in the lobectomy group.

From the published series, it emerged that the mean decrease in FEV1 ranged from $-9 \%$ to $-24 \%$ of the initial value (mean -18\%) within 2 months and from $-3 \%$ to $-13 \%$ (mean $-7 \%$ ) 12 months after segmentectomy. In 11 out of 13 studies, this reduction in lung function was significantly lower than that induced by lobectomy. Within 2 months after surgery, segmentectomy spared 3-10\% of initial FEV1, and after 12 months, 4-7\% (difference between the loss induced by lobectomy and the loss induced by segmentectomy). Interestingly, results from a few studies suggest that this functional benefit may not translate into lower rates of post-operative complications, regardless of the procedure used, open $[4,8,11$, 14] or VATS [6, 20-22].

The magnitude of the difference in functional loss between segmentectomy and lobectomy, which might be regarded as mild to moderate and may be disappointing, leads us to consider two points. First, the term segmentectomy encompasses the resection of one or more segments, and, as previously highlighted, three studies found a relationship between the decrease in lung function and the number of resected segments. In some series, the number of segments resected during sublobar resections may have been close to that resected during lobectomies. Interestingly, NOMORI et al. [12] compared the functional impact of the resection of $<2$ segments, $\geqslant 2$ segments, the left upper division or the left upper lobe. The differences in loss of FEV1 between groups were significant, except between the left upper division and left upper lobectomy groups. Second, differences in compensatory adaption of the remaining lung after lobectomy and segmentectomy could explain differences between lung volume resection and lung function preservation $[23,24]$. A better compensatory adaption of the remaining lung after lobectomy than after segmentectomy could reduce the functional benefit of segmentectomy. UEDA et al. [24] calculated CT-defined functional lung volume before and after lung resection. Lobectomy removed more functional lung volume than segmentectomy (24.5\% versus $11.6 \%)$. However, the loss of functional lung volume after segmentectomy was not significantly different from that after lobectomy (8.3\% versus $9.2 \%)$. Interestingly, the increase in both the ipsilateral and contralateral functional lung volume was more marked after lobectomy than after segmentectomy. The "function" of the segments rescued by segmentectomy decreased by $23 \%$ after surgery. Eventually, compensatory lung growth has also been discussed to explain the rather good compensatory adaptation after lobectomy $[25,26]$.

A low $\mathrm{FEV}_{1}$ is an independent predictive factor of complications, not only after major lung resection, but also after segmentectomy [27]. Surprisingly, while sublobar resections are recommended in patients with poor lung function, only three studies conducted specific functional studies in this high-risk population, including a total of 115 patients. Two of these studies showed that segmentectomy had better functional results than lobectomy $[8,11]$, whereas the third found no difference between the two procedures [7]. A mean gain in FEV1 of $12 \%$, or $0.12 \mathrm{~L}$, was described at 6 months in one series, the mechanism underlying this gain being unclear [11]. Interestingly, in a subgroup of patients with emphysema, an inverse relationship between the loss of FEV 1 and the predicted post-operative FEV 1 has been detected for lobectomy but not for segmentectomy [7]. The gain or at least the reduced loss in lung function induced by lobectomy in patients with severe emphysema may be attributable to a lung volume reduction effect [28]. The resection of an emphysematous segment, compared to that of a lobe, may not allow enough lung to expand after surgery to limit the functional loss. Taken as a whole, the results of these three studies do not firmly establish the functional benefit of segmentectomy over lobectomy in patients with poor lung function. Additional studies with a complete initial evaluation of lung function combined with lung imaging assessment may identify potential subgroups of patients who would benefit from either segmentectomy or lobectomy.

Eventually, the functional impact of open and VATS procedures should be discussed. In a recent series of 351 VATS lobectomies and segmentectomies, the decrease in pulmonary function at 12 months was low, the mean \pm SD loss of FEV1 being $6.9 \pm 10.3 \%$ and that of DLCO $6.9 \pm 14.8 \%$. However, the results associated with segmentectomy were not individualised [29]. A multivariate analysis performed in a consecutive series of 228 segmentectomies showed that open surgery, versus thoracoscopy, was an independent predictive factor of post-operative complications [27]. VATS reduces the loss of lung function after lobectomy [30,31], especially within the initial post-operative days, through decreased post-operative pain, improved chest wall mechanics and reduced inflammatory processes. These early days are regarded as critical determinants of post-operative morbidity and mortality [32, 33]. Large data-based series have indeed shown that VATS lobectomy can be performed with acceptable rates of morbidity and mortality in patients with predicted post-operative FEV1 or DLCO $<40 \%$ or $60 \%[32,34]$. As suggested by three studies showing low functional loss after VATS segmentectomy $[6,9,17]$, the functional benefit of segmentectomy may add to that of VATS. This needs to be confirmed in large series of patients, especially of patients with impaired lung function, and then may lead to a reconsideration of the lower functional limits for surgery. 


\section{Future prospects}

Besides surgery, other treatment modalities such as stereotactic ablative body radiotherapy (SABR) and radiofrequency ablation (RFA) can be offered to patients with stage I lung cancer. No proper comparison of SABR and segmentectomy functional consequences can be performed because of the lack of randomised trials. Several studies report PFT measured before and after SABR, but a comparison with surgical series is hazardous because of strong differences in patient characteristics (patients in SABR studies are older and have more degraded lung function) and study design [35-54]. The SABR PFT results suggest that the mean loss of lung function may be lower after SABR than after segmentectomy, but this needs to be confirmed. In fact, SABR patients show a small decrease in FEV1 and DLCO during the first weeks, but a marked functional loss at 2 years. This contrasts with surgery, which is characterised by a maximal decrease in FEV1 and DLCO during the first weeks and a reduction of the loss several months after treatment [50,54]. Another difference between surgery and SABR may be dispersion of the functional changes, which may be larger after SABR, a significant proportion of patients having improving lung function and another showing functional degradation. The occurrence rate of severe pulmonary toxicity after SABR, according to Common Terminology Criteria for Adverse Events (CTCAE) scoring, is low. Altogether, these data suggest that the functional tolerance of SABR, at least within the first months following radiotherapy, is quite good. However, whether SABR yields similar survival compared with surgical resection still remains to be established [55]. A potential flaw of SABR is indeed the lack of nodal dissection and sampling, which may lead to underestimation of the extent of disease.

A few PFT data from 135 lung cancer patients can be extracted from the RFA literature. Three studies found no significant change in mean forced vital capacity, FEV1 or DLCO until 12 months after RFA, but showed some dispersion of PFT values, like in SABR studies [56-58]. A fourth study found a significant but tiny reduction of PFT, the mean vital capacity 1 month and 3 months after RFA being at 93\% and 95\% of the baseline value [59]. Comparison of RFA with sublobar resection and SABR has been performed in two nonrandomised trials [40,60], but patient characteristics, including baseline PFT, differed significantly and none of the studies reported post-RFA PFT. Positioning of the treatment modalities for stage I lung cancer will partly rely on their functional cost, which needs to be carefully evaluated.

\section{Conclusions}

The published studies show that the long-term reduction ( $\geqslant 12$ months) in lung function induced by segmentectomy is very small, and a little smaller than that induced by lobectomy. However, this tiny difference may benefit lung cancer patients who may need subsequent lung resections. Within the 2 months after surgery, lung function reduction is mild to moderate, but also a little smaller than that induced by lobectomy. However, PFT monitoring within the early days after VATS segmentectomy, days that are critical determinants of post-operative morbidity, needs to be assessed. Two issues remain to be addressed: whether VATS segmentectomy may preserve lung function better than VATS lobectomy in patients with poor lung function, and whether this may translate into a lowering of the functional limit for surgery. In addition, the balance between benefits and risks related to sublobar resections and alternative therapeutic options such as SABR and RFA should be performed. One of the main problems is that implementation of randomised studies is quite impossible, the only few attempted having been prematurely closed due to poor recruitment $[61,62]$.

\section{References}

1 Brunelli A, Charloux A, Bolliger CT, et al. ERS/ESTS clinical guidelines on fitness for radical therapy in lung cancer patients (surgery and chemo-radiotherapy). Eur Respir J 2009; 34: 17-41.

2 Lim E, Baldwin D, Beckles M, et al. Guidelines on the radical management of patients with lung cancer. Thorax 2010; 65: Suppl. 3, iiil-iii27.

3 Brunelli A, Kim AW, Berger KI, et al. Physiologic evaluation of the patient with lung cancer being considered for resectional surgery: diagnosis and management of lung cancer, 3rd ed: American College of Chest Physicians evidence-based clinical practice guidelines. Chest 2013; 143: Suppl. 5, e166S-e190S.

4 Ginsberg RJ, Rubinstein LV. Randomized trial of lobectomy versus limited resection for T1 N0 non-small cell lung cancer. Lung Cancer Study Group. Ann Thorac Surg 1995; 60: 615-622.

5 Harada H, Okada M, Sakamoto T, et al. Functional advantage after radical segmentectomy versus lobectomy for lung cancer. Ann Thorac Surg 2005; 80: 2041-2045.

6 Hwang Y, Kang CH, Kim HS, et al. Comparison of thoracoscopic segmentectomy and thoracoscopic lobectomy on the patients with non-small cell lung cancer: a propensity score matching study. Eur J Cardiothorac Surg 2015; 48: $273-278$.

7 Kashiwabara K, Sasaki J, Mori T, et al. Relationship between functional preservation after segmentectomy and volume-reduction effects after lobectomy in stage I non-small cell lung cancer patients with emphysema. J Thorac Oncol 2009; 4: 1111-1116.

8 Keenan RJ, Landreneau RJ, Maley RH Jr, et al. Segmental resection spares pulmonary function in patients with stage I lung cancer. Ann Thorac Surg 2004; 78: 228-233. 
9 Kim SJ, Lee YJ, Park JS, et al. Changes in pulmonary function in lung cancer patients after video-assisted thoracic surgery. Ann Thorac Surg 2015; 99: 210-217.

10 Macke RA, Schuchert MJ, Odell DD, et al. Parenchymal preserving anatomic resections result in less pulmonary function loss in patients with stage I non-small cell lung cancer. J Cardiothorac Surg 2015; 10: 49.

11 Martin-Ucar AE, Nakas A, Pilling JE, et al. A case-matched study of anatomical segmentectomy versus lobectomy for stage I lung cancer in high-risk patients. Eur J Cardiothorac Surg 2005; 27: 675-679.

12 Nomori H, Cong Y, Sugimura H. Systemic and regional pulmonary function after segmentectomy. J Thorac Cardiovasc Surg 2016; 152: 747-753.

13 Okada M, Koike T, Higashiyama M, et al. Radical sublobar resection for small-sized non-small cell lung cancer: a multicenter study. J Thorac Cardiovasc Surg 2006; 132: 769-775.

14 Saito $\mathrm{H}$, Nakagawa $\mathrm{T}$, Ito $\mathrm{M}$, et al. Pulmonary function after lobectomy versus segmentectomy in patients with stage I non-small cell lung cancer. World J Surg 2014; 38: 2025-2031.

15 Suzuki H, Morimoto J, Mizobuchi T, et al. Does segmentectomy really preserve the pulmonary function better than lobectomy for patients with early-stage lung cancer? Surg Today 2017; 47: 463-469.

16 Takizawa T, Haga M, Yagi N, et al. Pulmonary function after segmentectomy for small peripheral carcinoma of the lung. J Thorac Cardiovasc Surg 1999; 118: 536-541.

17 Watanabe A, Ohori S, Nakashima S, et al. Feasibility of video-assisted thoracoscopic surgery segmentectomy for selected peripheral lung carcinomas. Eur J Cardiothorac Surg 2009; 35: 775-780.

18 Yoshikawa K, Tsubota N, Kodama K, et al. Prospective study of extended segmentectomy for small lung tumors: the final report. Ann Thorac Surg 2002; 73: 1055-1058.

19 Yoshimoto K, Nomori H, Mori T, et al. Quantification of the impact of segmentectomy on pulmonary function by perfusion single-photon-emission computed tomography and multidetector computed tomography. J Thorac Cardiovasc Surg 2009; 137: 1200-1205.

20 Ren M, Meng Q, Zhou W, et al. Comparison of short-term effect of thoracoscopic segmentectomy and thoracoscopic lobectomy for the solitary pulmonary nodule and early-stage lung cancer. Onco Targets Ther 2014; 7: 1343-1347.

21 Yamashita S, Tokuishi K, Anami K, et al. Thoracoscopic segmentectomy for T1 classification of non-small cell lung cancer: a single center experience. Eur J Cardiothorac Surg 2012; 42: 83-88.

22 Zhong C, Fang W, Mao T, et al. Comparison of thoracoscopic segmentectomy and thoracoscopic lobectomy for small-sized stage IA lung cancer. Ann Thorac Surg 2012; 94: 362-367.

23 Ali MK, Mountain CF, Ewer MS, et al. Predicting loss of pulmonary function after pulmonary resection for bronchogenic carcinoma. Chest 1980; 77: 337-342.

24 Ueda K, Tanaka T, Hayashi M, et al. Computed tomography-defined functional lung volume after segmentectomy versus lobectomy. Eur J Cardiothorac Surg 2010; 37: 1433-1437.

25 Butler JP, Loring SH, Patz S, et al. Evidence for adult lung growth in humans. N Engl J Med 2012; 367: 244-247.

26 Mizobuchi T, Wada H, Sakairi Y, et al. Spirometric and radiological evaluation of the remnant lung long after major pulmonary resection: can compensatory phenomena be recognized in clinical cases? Surg Today 2014; 44: 1735-1743.

27 Traibi A, Grigoroiu M, Boulitrop C, et al. Predictive factors for complications of anatomical pulmonary segmentectomies. Interact Cardiovasc Thorac Surg 2013; 17: 838-844.

28 Korst RJ, Ginsberg RJ, Ailawadi M, et al. Lobectomy improves ventilatory function in selected patients with severe COPD. Ann Thorac Surg 1998; 66: 898-902.

29 Kim SJ, Ahn S, Lee YJ, et al. Factors associated with preserved pulmonary function in non-small-cell lung cancer patients after video-assisted thoracic surgery. Eur J Cardiothorac Surg 2016; 49: 1084-1090.

30 Kaseda S, Aoki T, Hangai N, et al. Better pulmonary function and prognosis with video-assisted thoracic surgery than with thoracotomy. Ann Thorac Surg 2000; 70: 1644-1646.

31 Nakata M, Saeki H, Yokoyama N, et al. Pulmonary function after lobectomy: video-assisted thoracic surgery versus thoracotomy. Ann Thorac Surg 2000; 70: 938-941.

32 Burt BM, Kosinski AS, Shrager JB, et al. Thoracoscopic lobectomy is associated with acceptable morbidity and mortality in patients with predicted postoperative forced expiratory volume in 1 second or diffusing capacity for carbon monoxide less than 40\% of normal. J Thorac Cardiovasc Surg 2014; 148: 19-28.

33 Varela G, Brunelli A, Rocco G, et al. Measured FEV1 in the first postoperative day, and not ppoFEV1, is the best predictor of cardio-respiratory morbidity after lung resection. Eur J Cardiothorac Surg 2007; 31: 518-521.

34 Ceppa DP, Kosinski AS, Berry MF, et al. Thoracoscopic lobectomy has increasing benefit in patients with poor pulmonary function: a Society of Thoracic Surgeons Database analysis. Ann Surg 2012; 256: 487-493.

35 Alberts L, El Sharouni SY, Hofman FN, et al. Changes in pulmonary function after stereotactic body radiotherapy and after surgery for stage I and II non-small cell lung cancer, a description of two cohorts. Anticancer Res 2015; 35: 6773-6779.

36 Baumann P, Nyman J, Hoyer M, et al. Stereotactic body radiotherapy for medically inoperable patients with stage I non-small cell lung cancer - a first report of toxicity related to COPD/CVD in a non-randomized prospective phase II study. Radiother Oncol 2008; 88: 359-367.

37 Bishawi M, Kim B, Moore WH, et al. Pulmonary function testing after stereotactic body radiotherapy to the lung. Int J Radiat Oncol Biol Phys 2012; 82: e107-e110.

38 Bral S, Gevaert T, Linthout N, et al. Prospective, risk-adapted strategy of stereotactic body radiotherapy for early-stage non-small-cell lung cancer: results of a Phase II trial. Int J Radiat Oncol Biol Phys 2011; 80: 1343-1349.

39 Collins BT, Vahdat S, Erickson K, et al. Radical cyberknife radiosurgery with tumor tracking: an effective treatment for inoperable small peripheral stage I non-small cell lung cancer. J Hematol Oncol 2009; 2: 1.

40 Crabtree T, Puri V, Timmerman R, et al. Treatment of stage I lung cancer in high-risk and inoperable patients: comparison of prospective clinical trials using stereotactic body radiotherapy (RTOG 0236), sublobar resection (ACOSOG Z4032), and radiofrequency ablation (ACOSOG Z4033). J Thorac Cardiovasc Surg 2013; 145: 692-699.

41 Eriguchi T, Takeda A, Sanuki N, et al. Stereotactic body radiotherapy for T3 and T4N0M0 non-small cell lung cancer. J Radiat Res 2016; 57: 265-272.

42 Ferrero C, Badellino S, Filippi AR, et al. Pulmonary function and quality of life after VMAT-based stereotactic ablative radiotherapy for early stage inoperable NSCLC: a prospective study. Lung Cancer 2015; 89: 350-356. 
43 Fritz P, Kraus HJ, Blaschke T, et al. Stereotactic, high single-dose irradiation of stage I non-small cell lung cancer (NSCLC) using four-dimensional CT scans for treatment planning. Lung Cancer 2008; 60: 193-199.

44 Guckenberger M, Kestin LL, Hope AJ, et al. Is there a lower limit of pretreatment pulmonary function for safe and effective stereotactic body radiotherapy for early-stage non-small cell lung cancer? J Thorac Oncol 2012; 7: $542-551$.

45 Guckenberger M, Klement RJ, Kestin LL, et al. Lack of a dose-effect relationship for pulmonary function changes after stereotactic body radiation therapy for early-stage non-small cell lung cancer. Int J Radiat Oncol Biol Phys 2013; 85: 1074-1081.

46 Henderson M, McGarry R, Yiannoutsos C, et al. Baseline pulmonary function as a predictor for survival and decline in pulmonary function over time in patients undergoing stereotactic body radiotherapy for the treatment of stage I non-small-cell lung cancer. Int J Radiat Oncol Biol Phys 2008; 72: 404-409.

47 Mangona VS, Aneese AM, Marina O, et al. Toxicity after central versus peripheral lung stereotactic body radiation therapy: a propensity score matched-pair analysis. Int J Radiat Oncol Biol Phys 2015; 91: 124-132.

48 Ohashi T, Takeda A, Shigematsu N, et al. Differences in pulmonary function before vs. 1 year after hypofractionated stereotactic radiotherapy for small peripheral lung tumors. Int J Radiat Oncol Biol Phys 2005; 62: 1003-1008.

49 Stephans KL, Djemil T, Reddy CA, et al. Comprehensive analysis of pulmonary function test (PFT) changes after stereotactic body radiotherapy (SBRT) for stage I lung cancer in medically inoperable patients. $J$ Thorac Oncol 2009; 4: 838-844.

50 Stone B, Mangona VS, Johnson MD, et al. Changes in pulmonary function following image-guided stereotactic lung radiotherapy: neither lower baseline nor post-SBRT pulmonary function are associated with worse overall survival. J Thorac Oncol 2015; 10: 1762-1769.

51 Takeda A, Enomoto T, Sanuki N, et al. Reassessment of declines in pulmonary function $\geqslant 1$ year after stereotactic body radiotherapy. Chest 2013; 143: 130-137.

52 Videtic GM, Reddy CA, Sorenson L. A prospective study of quality of life including fatigue and pulmonary function after stereotactic body radiotherapy for medically inoperable early-stage lung cancer. Support Care Cancer 2013; 21: 211-218.

53 Woody NM, Stephans KL, Marwaha G, et al. Stereotactic body radiation therapy for non-small cell lung cancer tumors greater than $5 \mathrm{~cm}$ : safety and efficacy. Int J Radiat Oncol Biol Phys 2015; 92: 325-331.

54 Stanic S, Paulus R, Timmerman RD, et al. No clinically significant changes in pulmonary function following stereotactic body radiation therapy for early-stage peripheral non-small cell lung cancer: an analysis of RTOG 0236. Int J Radiat Oncol Biol Phys 2014; 88: 1092-1099.

55 McDonald F, De Waele M, Hendriks LE, et al. Management of stage I and II nonsmall cell lung cancer. Eur Respir J 2017; 49: 1600764.

56 Dupuy DE, Fernando HC, Hillman S, et al. Radiofrequency ablation of stage IA non-small cell lung cancer in medically inoperable patients: results from the American College of Surgeons Oncology Group Z4033 (Alliance) trial. Cancer 2015; 121: 3491-3498.

57 Lanuti M, Sharma A, Digumarthy SR, et al. Radiofrequency ablation for treatment of medically inoperable stage I non-small cell lung cancer. J Thorac Cardiovasc Surg 2009; 137: 160-166.

58 Lencioni R, Crocetti L, Cioni R, et al. Response to radiofrequency ablation of pulmonary tumours: a prospective, intention-to-treat, multicentre clinical trial (the RAPTURE study). Lancet Oncol 2008; 9: 621-628.

59 Tada A, Hiraki T, Iguchi T, et al. Influence of radiofrequency ablation of lung cancer on pulmonary function. Cardiovasc Intervent Radiol 2012; 35: 860-867.

60 Safi S, Rauch G, op den Winkel J, et al. Sublobar resection, radiofrequency ablation or radiotherapy in stage I non-small cell lung cancer. Respiration 2015; 89: 550-557.

61 Louie AV, Palma DA, Dahele M, et al. Management of early-stage non-small cell lung cancer using stereotactic ablative radiotherapy: controversies, insights, and changing horizons. Radiother Oncol 2015; 114: 138-147.

62 Louie AV, van Werkhoven $\mathrm{E}$, Chen $\mathrm{H}$, et al. Patient reported outcomes following stereotactic ablative radiotherapy or surgery for stage IA non-small-cell lung cancer: results from the ROSEL multicenter randomized trial. Radiother Oncol 2015; 117: 44-48. 